\title{
Del giro ontológico a la ontología relacional y política, una mirada a la propuesta de Arturo Escobar
}

\section{Diana Alejandra Díaz Guzmán**}

\section{Resumen}

Se analiza la apuesta ontológica de Arturo Escobar a partir de dos formas en las que esta se expresa, para vislumbrar los alcances y limitaciones de esta concepción ontológica. La primera concepción radica en lo que el autor denomina ontología relacional y la segunda versa en la llamada ontología política. El texto está dividido en cuatro apartados, el primero introduce al lector a lo que representa la pregunta por el ser, haciendo hincapié en Martin Heidegger. El segundo expone brevemente el contexto que se puede evidenciar en la apuesta académica del antropólogo colombiano a través del giro ontológico, desarrollado desde la antropología, en el que se destaca una crítica al paradigma occidental dualista naturaleza/cultura y, a su vez, de la teoría decolonial que denuncia la Modernidad y la vigencia de la colonialidad de ser, para así poder comprender la propuesta de la ontología relacional de Escobar. El tercer apartado expresa desde las categorías de territorio y pluriverso una premisa fundamental: pensar lo político presupone una ontología, es decir, una visión de mundo sobre lo que es y está, de esta

* Este artículo es resultado de las reflexiones e investigaciones personales que ha realizado la autora en torno a la ontología y la política. Citar como: Díaz Guzmán, D. A. (2020). Del giro ontológico a la ontología relacional y politica, una mirada a la propuesta de Arturo Escobar. Cuadernos de Filosofía Latinoamericana, 41(123), 99-122. Dol: https://doi.org/10.15332/25005375/5991

* Licenciada en Filosofía de la Universidad Pedagógica Nacional. En la actualidad es estudiante de la Maestría en Filosofía Latinoamericana de la Universidad Santo Tomás.

Correo electrónico: ddiaz.sisifo@gmail.com 
manera se articula el proyecto de la ontología desde la relacionalidad con luchas que reivindican los mundos y los derechos de las comunidades; en el cuarto y último apartado se exponen los alcances y límites de la ontología de Escobar, así como caminos posibles para considerar en investigaciones futuras.

Palabras clave: ontología relacional, ontología política, colonialidad, giro ontológico, comprensión existencial, territorialización.

\section{From the Ontological Turn to Relational and Political Ontology: A Review of Arturo Escobar's Proposal}

\section{Abstract}

This article analyses Arturo Escobar's ontological approach according to the two main ways in which it is expressed, so as to identify its scope and limitations. The first way is rooted in the author's concept of relational ontology and the second one concerns so-called political ontology. The text is divided into four sections. The first section, focusing on Martin Heidegger, introduces the reader the meaning of the question of Being. So as to elucidate Escobar's proposal of relational ontology, the second section briefly expounds the academic position of the Colombian anthropologist, which looks at the ontological from the point of view of anthropology, upholding a criticism of the dualist nature/culture Western paradigm and, in turn, of decolonial theories that denounce Modernity and the validity of the colonialism of being. By means of the categories of territory and pluriverse, the third section touches upon a fundamental premise: that all thought about the political presupposes an ontology, that is, a worldview which explains what exists; this is how an ontological project is articulated, through relationality, with struggles that affirm the worlds and the rights of communities. The fourth and last section is an assessment of the scope and limits of Escobar's ontology, as well as of possible opportunities for future research.

Keywords: Relational Ontology, Political Ontology, Coloniality, Ontological Turn, Existential Understanding, Territorializing. 
Somos la continuidad de la tierra, miremos desde el corazón de la tierra. MARCUS YULE, citado por ARTURO ESCOBAR

\section{Introducción}

Nuestra América es actualmente un continente negado debido a la falta de autodeterminación y subsumido bajo las lógicas neoliberales de la globalización. Sin embargo, este continente ha aprendido a reflexionar sobre sí mismo desde diversos campos académicos y desde la vida misma. Nuestra América ha sumado sus esfuerzos teóricos para comprender(se) y denunciar no el desencanto y el proyecto inacabado de la Modernidad (Jürgen Habermas), sino el mito de la Modernidad (Enrique Dussel), e incluso ir más allá de él, para argumentar cómo el colonialismo se terminó, pero no la colonialidad (Aníbal Quijano). La construcción de una crítica a un sistema de pensamiento y un conjunto de prácticas eurocéntricas que siguen vigentes inicia con volver la mirada a la Modernidad y su proyecto ontológico.

En este artículo se partirá de lo más simple: toda epistemología presupone una ontología, de manera que la forma en la que se conoce y se organiza el mundo depende del horizonte de significación que se le proporcione al mundo mismo y a todo lo que lo compone, constituye, complementa y forma. Actualmente, se considera que la ontología no puede reducirse simplemente al estudio del ser en cuanto ser, por ello esta se asocia a la concepción de mundo en relación con la cultura. Lo anterior, por lo menos, ha servido como punto de partida en disciplinas como la antropología, específicamente en el "giro ontológico".

Los antropólogos hablan de giro ontológico desde hace treinta años, cuando la antropología comenzó a asumir sus estudios disciplinares de manera interdisciplinar con las categorías y conceptos que la ontología y la metafísica, indirectamente, ofrecen. Es decir, este giro proporcionó a la antropología, así como a la filosofía latinoamericana, la posibilidad de cuestionar críticamente la cultura occidental. A su vez, provocó un cambio en la forma de leer o interpretar el mundo, desde una transformación radical de horizonte en el que, hasta el símbolo, algo tan propio de la antropología, es interpretado ontológicamente. Sin embargo, tal como lo aclaran Silla y Renoldi (2016), la ontología aún es un término confuso para la antropología. 
Vale la pena mencionar que ya en el siglo xx, Martin Heidegger denunció el olvido en el que había caído la pregunta por el ser y la importancia de cuestionarse por su sentido. La investigación científica, cualquiera que sea, abarca una determinada región del ser, debido al acercamiento que se hace a una zona específica del ente que porta el ser. Sin embargo, comprender en su máxima expresión al ente, en tanto que está siendo, ha sido la labor milenaria de la ontología como rama de la filosofía. Por eso, la advertencia lúcida del filósofo alemán aún resuena en el siglo xxi:

Todo intento por conocer al ente en cuanto que ente, [parte] de un acuerdo previo sobre lo que "propiamente queremos decir con esta expresión 'ser". Por lo tanto, [...] se puede decir que la pregunta por el ser ha de enmarcarse antes de todo conocimiento científico y ontológico, ya que si no llegamos a una claridad acerca de lo que queremos decir al referirnos al ser no llegaremos a una claridad respecto de los conceptos ulteriores a este. (Heidegger, 2009, p. 32)

Lo anterior es de suma importancia si realmente se quieren tender puentes interdisciplinares, ya que no se está hablando en el mismo lenguaje entre antropólogos y filósofos, esto es evidente cuando se hace referencia a conceptos tales como: "ontología”, "ser", "mundo", entre otros. Los aportes realizados por algunos antropólogos del giro ontológico enriquecen a la filosofía, pero aún así es necesario nutrir la discusión con la pregunta más antigua y pensada por los filósofos: Tí đó őv (‘¿qué es el ser?’).

Por ejemplo, en el libro vir de la Metafísica, Aristóteles se preguntaba por el ser que está siendo y no puede dejar de ser, por lo que hace que la cosa sea lo que es y no otra cosa, en realidad la pregunta es por el ser que está siendo ya algo. Cabe mencionar que, para los griegos óv ('ser') es un participio activo que forma parte de la conjugación verbal como acción y no está sustantivada, así pues, el ser se manifiesta en lo que está andando, está hablando, está viviendo, lo que está siendo. Desde luego, Aristóteles

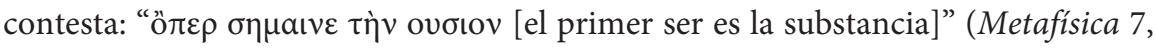
1028a, 20-25), la ousía (la unidad entre forma y materia). Aunque, “Tò öv $\lambda \varepsilon \gamma \varepsilon \tau \alpha \iota$ $\pi 0 \lambda \lambda \alpha \chi \omega \varsigma$ [el ser se dice de muchos sentidos]" (Metafísica 7, 1028a, 10). El ser, en tanto que ser siendo, se dice de muchos sentidos, lo anterior hace referencia a las nueve categorías bajo las cuales se expresa el ser (substancia, cantidad, relación, cualidad, acción, pasión, tiempo, lugar, situación y hábito). En el siglo xx, Heidegger toma distancia de estas formas de apalabrar el ser, usadas desde Platón hasta la edad moderna. 
Para Heidegger, la comprensión del mundo implica una comprensión de sí mismo y viceversa, este proceso es, ante todo, conocimiento, puesto que surge como posibilidad del modo de ser-en-el-mundo, es decir, es algo que ya está siendo y en el que el Dasein (el ser del hombre) se encuentra inmerso como ser que participa en el mundo. En consecuencia, la primera relación del Dasein con el mundo óntico se da existencialmente, según Heidegger:

En primer lugar, una primacía óntica: el Dasein está determinado en su ser por la existencia. En segundo lugar, una primacía ontológica: en virtud de su determinación por la existencia, el Dasein es ontológico en sí mismo [...] el Dasein tiene una tercera primacía: la de ser condición de posibilidad ónticoontológica de todas las ontologías. (Heidegger, 2009, p. 34)

En consecuencia, es importante tener en cuenta que el Dasein está determinado por la existencia. Asimismo, en virtud de esta, él es ontológico, debido a la relación de ser con su ser, así que el Dasein participa en el mundo óntico y ontológico. Dicho de otra manera, el Dasein es un ser en el mundo y por ello tras encontrarse con los otros entes en el mundo, se halla con la particularidad de que a diferencia de ellos él posee un cierto nivel de apertura hacia el ser en general, lo comprende de alguna manera.

Ahora bien, se podría decir que para Heidegger (2009) la investigación que realiza el Dasein sobre su existencia tiene dos pasos, el primero radica en la comprensión existentiva que se encuentra en un plano óntico, puesto que el Dasein se pregunta por su existir sin indagar por la estructura ontológica, por el ser, ya que lo que busca es comprender la existencia óntica en la que participa; el segundo es la comprensión de existencialidad que se halla en un plano ontológico, puesto que a diferencia del anterior se busca indagar por la estructura propia de lo constitutivo del ser. Cabe mencionar que el primero inevitablemente llevará al segundo, en cuanto que el Dasein trae consigo la comprensión de su ser.

En consecuencia, se puede afirmar que el ente humano es un Dasein (ser-ahí), un ente que está situado en el mundo, eyectado en este y que, además, se pregunta y se preocupa por su ser. Aunque, como lo advierte Heidegger (2009), es posible que el hombre se olvide de su ser para consagrarse al mundo de los entes, más aún hay un ser que se pregunta por el ser: el hombre, de ahí que Heidegger realice una antropología existencial en Ser y tiempo. Es por ello, que al considerar nuevas apuestas antropológicas, 
como la de Escobar y el giro ontológico, resulta fundamental partir de la filosofía en la que, precisamente, hay un hombre que se pregunta por el ser y que, a su vez, es ente existencial que está arrojado en el mundo y que a partir allí realiza una construcción de sentido, sobre la cual estas apuestas antropológicas quieren hacer énfasis.

\title{
Del giro ontológico a la ontología relacional de Arturo Escobar
}

\begin{abstract}
Ahora bien, la antropología empieza a contemplar que no es posible establecer una distinción radical entre las condiciones objetivas y las subjetivas, lo real y lo construido, la naturaleza y la cultura. Por tal motivo, antropólogos como Arturo Escobar identifican una estrecha relación entre ontología y cultura, esto trae como consecuencia que su formación académica antropológica, con la que se vislumbra e interpreta la ontología, no logre establecer una definición común con la filosofía. Sin embargo, un aporte teórico de la filosofía podría ser la categoría: comprensión existencial, pues esta ofrece un fundamento a lo que Escobar propone en la ontología relacional, como se verá más adelante.
\end{abstract}

No obstante, a propósito del pensar desde América Latina, la propuesta de Escobar nace también desde un proyecto transdisciplinar que inició labores en 1996 en la Universidad del Estado de Nueva York. Aníbal Quijano e Inmanuel Wallerstein trabajaron conjuntamente para inaugurar seminarios y un congreso en donde se reflexionaría sobre las herencias coloniales en América Latina, sumado al análisis del sistema-mundo, desarrollado por la sociología. Desde ese primer congreso hasta 2004 participaron varios intelectuales de diferentes partes y disciplinas de América (Enrique Dussel, Walter Mignolo, Edgardo Lander, Ramón Grosfoguel, Santiago Castro-Gómez, Boaventura de Sousa Santos), uno de los organizadores de esos encuentros fue Escobar. Posiblemente en este diálogo interdisciplinar, el antropólogo colombiano fue profundamente influenciado por De Sousa Santos, ya que lo referencia en múltiples textos y conferencias. Asimismo, su pensamiento se enmarca en este proyecto decolonial.

Una vez aclarado lo anterior, el contexto de la disciplina misma y el proceso del autor desde el giro decolonial, se puede ahondar en los fundamentos para pensar en una ontología relacional. Como ya se había mencionado, para Escobar (2012) hay 
una equivalencia entre ontología y cultura, sin embargo, el autor aclara que hay dos formas de entender la cultura: como estructura simbólica (CES), propia de la ontología dualista de la Modernidad, o como diferencia radical (CDF), que permite resaltar la relacionalidad de todo lo que existe.

Cabe mencionar que la reflexión académica del antropólogo colombiano está profundamente enlazada con una apuesta política de empoderamiento de las comunidades que están siendo vulneradas en sus derechos territoriales e identitarios, tales como las comunidades afrodescendientes en el Pacífico. Por ello, existe un interés de alto grado de relevancia en hablar de la ontología relacional, pues esta sirve de fundamento $\mathrm{y}$, a su vez, de defensa de las concepciones y prácticas comunitarias y populares. De una u otra forma, el autor está pensando en clave de ontología política, para los movimientos sociales.

Escobar es crítico de la Modernidad, ya que esta dio lugar a la ontología dual, en la que se refleja la concepción de la CES, en cuanto que se concibe al mundo de un modo único, solo hay una realidad, por ende, se trata de una homogenización del universo. Cabe mencionar que se habla de dualidad no como un reconocimiento de dos partes, sino como una yuxtaposición en la que debe primar una parte sobre la otra. En palabras del autor:

En el fundamento de esta creencia [un mundo único] hay dos grandes procesos interrelacionados: ciertas premisas ontológicas sobre lo que constituye lo real (especialmente la unicidad del mundo natural) y procesos históricos de hegemonía y poder que han permitido a esta concepción de un mundo naturalizarse y esparcirse a lo largo y ancho de territorios socionaturales y calar en los suelos culturales de los pueblos del mundo. (Escobar, 2012, p. 8)

Así pues, las premisas ontológicas modernas representan de manera explícita las concepciones de mundo en las que se constituye lo real como unidireccional y unidimensional. Asimismo, dichas concepciones se disputan en lo real a través de la historia vista como dominado y dominador, en cuanto que es claro que el hombre blanco europeo occidental (sexo, raza y origen) postuló, desde Descartes, la necesidad de constituirse como un único sujeto que domina el mundo que le rodea. Así, todo lo que sea distinto es concebido como un objeto que se puede poseer y manipular, de ahí que exista esta dualidad también para la concepción de naturaleza y cultura. 
Complementando lo anterior, se evidencia desde una concepción moderna que la naturaleza es algo que se rige solamente por leyes universales establecidas por el paradigma científico y es igual para todas las culturas. De manera que desde este enfoque no tienen validez las creencias de los distintos mundos simbólicos, en cuanto que esto sería algo de origen subjetivo y debe primar lo objetivo e impersonal, como las leyes universales. En este orden de ideas, la concepción de la naturaleza de los pueblos no occidentales era incomprendida por el paradigma moderno de las ciencias tales como la antropología, ya que tal concepción se enmarcaba como una cuestión animista, es decir, una visión "primitiva” en la que el mundo natural era dotado de vida o movimiento, y se desconocía otro modo de comprensión y de validez. Así, "[1]as discusiones referidas al naturalismo o al animismo, y al pensamiento individual o social, de una $\mathrm{u}$ otra manera, adrede o no, fueron una forma de distinguir lo occidental y moderno, por un lado, y lo primitivo y tradicional, por el otro" (Silla y Renoldi, 2016, p. 11).

Esta concepción sugiere que existen varias culturas pero solo una naturaleza. Solo una puede ser, pues si hubieran otras serían no-ser, en cuanto que no estarían regidas por las normas lógico formales del pensamiento occidental, estarían erradas. Dicho de otra manera:

En el fundamento mismo de la operación moderna dualista que descalifica otros mundos, Ingold es explícito en demostrar cómo funciona esta operación: por un lado, se afirma la unicidad de la realidad (solo existe un mundo natural); segundo, se postula la existencia de múltiples concepciones de este mundo, es decir, de "culturas" que "conocen" esta realidad única de diversas maneras (relativismo cultural), y tercero, toda la operación es legitimada por la existencia de supra-racionalidad ("razón universal”), que solo Occidente posee y que es la única garantía de verdad sobre esa realidad. (Escobar, 2012, p. 10)

De esta manera, la ciencia es la única capaz de indagar por el funcionamiento de la naturaleza, desde un análisis racional, y la antropología solo debe comparar las visiones de mundo de las culturas (antropología multiculturalista).

Ahora bien, en este punto se complejiza la premisa de la que partimos (toda epistemología presupone una ontología), ya que las relaciones del ser humano con su entorno no son las mismas, es decir, no son homogéneas, pues dependen del territorio, de la concepción de la naturaleza y de la sociedad misma, de la concepción que se pueda 
tener del mundo. El giro ontológico postula una antropología desde el multinaturalismo, como la desarrollada por Viveiros de Castro.

El giro ontológico y la visión decolonial aciertan en evidenciar que los mundos simbólicos de origen intersubjetivo - en cuanto que en América Latina el sujeto se piensa como parte de una comunidad, tal sujeto, equiparado con Occidente, no es individual, es un sujeto colectivo- no son simples fabricaciones de la mente, sino que, por el contrario, develan otras construcciones de mundo vinculadas a la diversidad étnica, cultural y las distintas formas de organización social. De manera que la relación de los pueblos no-occidentales con la naturaleza debe comprenderse desde la expresión de las categorías fundamentales que organizan y dotan de sentido las relaciones entre los seres humanos y los ecosistemas en donde están inmersos, por tanto, existen múltiples mundos.

En este orden de ideas, para Escobar la visión dualista moderna niega las diferentes visiones de mundo, en cuanto que para establecer la validez de una estructura simbólica, sería necesario deslegitimar todas aquellas que no sean idénticas y ahí radica el error, puesto que desde la cultura como diferencia radical se establecería que aunque hubiera una distinción radical de mundos estos estarían interrelacionados. Además, Escobar (2012) advierte que los estudios culturales latinoamericanos que han tratado de problematizar la imbricación entre cultura, discurso y poder han sido incapaces de gravitar fuera de la CES, lo que ha traído como consecuencia que ese entendimiento de lo cultural sea un sentido común naturalizado.

Esta concepción sería más apropiada, en la medida en que amplía el horizonte de comprensión, pues en este no hay una sola naturaleza de carácter cientificista, sino que hay múltiples naturalezas que son desplegadas a partir de una cultura que interpreta. Dicha interpretación depende de la experiencia vital en la que se encuentre una cultura en relación con la naturaleza. Como lo manifiesta la antropóloga argentina Florencia Tola:

Por otro lado, esta dicotomía [naturaleza y cultura] y los rasgos asociados a ella fueron reformulados y dieron paso a la elaboración de ontologías en las que lo dado (la naturaleza) y lo construido (la cultura) remiten a realidades diferentes y en las que se produce incluso una inversión total de los postulados 
de la ontología naturalista: "la cultura es el referente alrededor del cual se despliegan una pluralidad de naturalezas". (Tola, 2016, p. 133)

Esto conlleva profundas implicaciones para los antropólogos que pretenden hacer hincapié en la ontología, puesto que no se trata solo de una representación del mundo, sino de una profunda contemplación desde la existencia vital en la que se piensa y se vive. Como lo manifestó Dussel (2016) en su estudio de Ser y tiempo, todo parte de una comprensión existencial (como se mencionó en la introducción). En este sentido, es fundamental reflexionar que a partir de lo práctico cotidiano se devela el ser como fundamento del mundo. De ahí que la comunidad lleve a cabo la comprensión existencial, en cuanto que desde la cotidianidad le da lugar al núcleo mítico ontológico situado en la existencia.

De esta manera, con Dussel (2016), quien retoma a Husserl y a Heidegger, el primer nivel ontológico es el Lebenswelt ('mundo de la vida'), ya que el sujeto que es miembro de una comunidad se encarga de constituir el sentido de todo lo que lo rodea a partir de una totalidad que lleva el nombre de mundo. Es por esto que: "de una manera precisa llamaremos ontología a la reflexión acerca del mundo cotidiano como totalidad de sentido práctico, es decir, como comprensión del 'ser' siendo el 'ser' el fundamento práctico cotidiano del mundo" (Dussel, 2016, p. 30).

Quizás es por todo lo dicho anteriormente que tanto el planteamiento de Escobar como el giro ontológico acuden a poner como equivalentes ontología y mundo, en el sentido expuesto, es decir, porque se entiende por "ser" el fundamento del mundo. Así, la comprensión práctica de la vida comunitaria y propia presenta "lo que es", lo que está siendo, como un horizonte ineludible bajo el cual se percibe la totalidad de sentido llamada mundo (Dussel, 2016).

En este sentido, la labor del antropólogo que cree en el giro ontológico presupone, como lo identifica Tola (2016), tomar en serio los diferentes mundos, no como metáforas o enunciados errados por no asemejarse a la única visión de naturaleza/mundo. Por ello, el ser se manifiesta de múltiples maneras, según la relacionalidad que se dé a través del conjunto de significados y prácticas de las culturas. Así, esta apertura proporciona al pensar desde el giro ontológico que toda construcción de mundo tiene de por sí validez ontológica, en cuanto que refleja una profunda relacionalidad con todo lo que existe. Sin embargo, el reto estaría en crear las categorías universales para 
entablar una conversación que permita seguir ampliando el horizonte de comprensión existencial y vital de los diferentes mundos, que pueblan el mundo, para no perpetuar el dominio del ser es y el no-ser no es bajo lógicas homogeneizantes.

Por consiguiente, el antropólogo colombiano continúa vislumbrando que la concepción de la ontología debe presuponer, entonces, la noción del pluriverso, para problematizar la noción de universo naturalizada por la cEs. Por ello, el antropólogo aclara que no se está hablando de ontología como la esencia del ser, de lo real, sino que retoma la definición planteada por Blaser:

Primero, ontología se refiere a aquellas premisas que los diversos grupos sociales mantienen sobre entidades que realmente existen en el mundo. [...] Segundo nivel es que las ontologías se enactúan a través de prácticas; es decir, no solamente existen como imaginarias, ideas, discursos o lo que se quiera, sino que son corporizadas en prácticas. Estas prácticas crean verdaderos mundos - de aquí que a veces los conceptos de mundo y ontología se usen de forma equivalente- Por ejemplo: la enacción de una ontología dentro de la cual la montaña es un ser discreto e inerte, sin vida, lleva a su eventual destrucción como en la minería a cielo abierto de oro o carbón. Tercero, las ontologías se manifiestan en historias (o narrativas) que permiten entender con mayor facilidad las premisas sobre qué tipo de entidades y relaciones conforman el mundo. (Escobar, 2012, p. 12)

Así pues, la definición proporcionada por Escobar permite dilucidar que las construcciones de mundo se entrelazan con las entidades mundanas (las del entorno natural) y supramundanas (dios/es) para materializarse en prácticas sociales concretas, lo anterior también deja entrever que la ontología no es un concepto abstracto cuyo campo de acción es el pensamiento, la ontología tampoco es aquí la comprensión de un ser ideal que no está en este mundo, sino que el ser sería la relación con el mundo en el que la comunidad está arrojada. Cabe mencionar en este punto que Escobar (2015a) comprende a la comunidad no solo como un conjunto de humanos, sino que se incluye también a los animales, las montañas, los espíritus (dependiendo del territorio), los no-humanos. Nuevamente, el ser se manifiesta en todo lo que está siendo en el territorio.

No obstante, dimensionar la relacionalidad sin hablar del territorio en el pensamiento de Escobar sería insultar su aporte como investigador comprometido con la realidad 
social, ya que él también cree, como las comunidades con las que ha trabajado, que el campo de la política debe ser pensado también para los no-humanos, pues la comunidad está arrojada en un lugar específico, está en el territorio. De manera que:

\begin{abstract}
El territorio como condición de posibilidad y las diversas lógicas comunales que con frecuencia las subyacen. [...] En estas ontologías, los territorios son espacios-tiempos vitales de toda comunidad de hombres y mujeres, [...] también es el espacio-tiempo de interrelación con el mundo natural que circunda y es parte constitutivo de él. (Escobar, 2015a, p. 96)
\end{abstract}

Nuevamente se evidencia la ruptura con la Modernidad, pues el hombre moderno establece una lógica sujeto-objeto, cultura-naturaleza, que implica dominar aquello que está fuera de lo corporal del sujeto. Sin embargo, desde esta ontología el mundo natural no refleja una relación de dominación, sino que se revela como una relación social, en la medida en que las entidades que pueblan el territorio se manifiestan como vivas, nuevamente: comprensión desde un horizonte de experiencia vital. Reconstruyendo la definición del ser para Escobar en mis palabras, el ser es relación práctica entre una comunidad (humanos y no humanos) con y en el territorio en el que está participando.

De esta manera, el antropólogo colombiano continúa defendiendo la tesis de los territorios como mundos relacionales, todo es relación con y en el territorio para una comunidad, el ejemplo proporcionado por Escobar (2015b) para evidenciar el entramado relacional es la siguiente imagen:

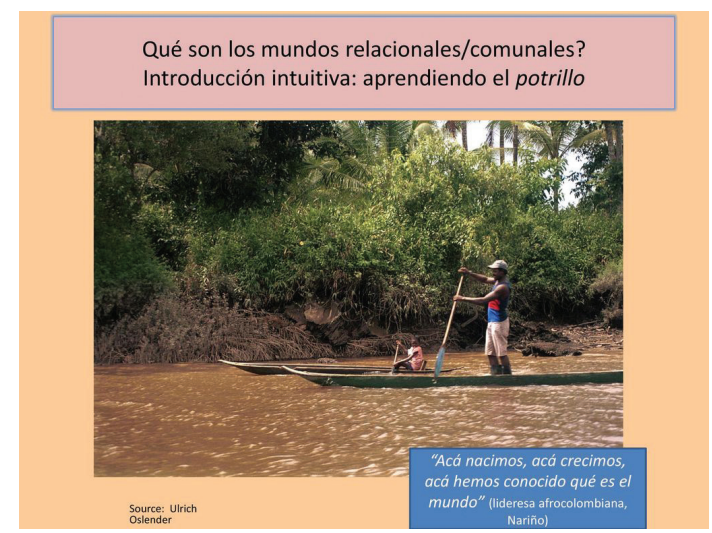

Figura 1. Entramado relacional en la ontología de Arturo Escobar Fuente: Escobar (2015b). 
En la anterior imagen se puede contemplar, según el antropólogo colombiano, no solo la relación de padre e hija, sino algo más profundo: un entramado de relaciones. Vemos a un señor con una niña, con las canoas, con el mangle - cortado en la época propicia para que su madera fuera útil para la canoa-, que saben el ritmo del río, que saben que allí están los dioses, las diosas, el inframundo y el supramundo, que hay cangrejos y rizomas, que hay agua, lluvia, sol, es decir, en cada acto de remar ellos están construyendo un mundo relacional (Escobar, 2015b).

Aunque no se explica en la conferencia, esa frase tan diciente que está en el costado derecho en la parte inferior de la figura 1 es muy contundente para el análisis propuesto en este artículo, ya que en y con el territorio se construyen las visiones de mundo, cuando se dice se construye en y con se hace referencia a unas prácticas locales tradicionales. El mundo es profundamente territorializado, pues es lo que está-siendo, por ello hay múltiples mundos, pluriversos. Así:

Cada mundo es enactuado por sus prácticas específicas, sin duda en contextos de poder tanto a su interior como con respecto a otros mundos. Estos mundos constituyen un pluriverso, es decir, un conjunto de mundos en conexión parcial los unos con los otros, y todos enactuándose y desenvolviéndose sin cesar. Como lo demuestra la perseverancia de mundos relacionales, siempre hay algo en todos estos mundos que "excede" la influencia de lo moderno; este "exceso" que resiste definición y reducción a lo moderno es también un fundamento importante de la ontología política y de la práctica política ontológica. (Escobar, 2015a, p. 97)

En consecuencia, queda definido lo que se entiende por ontología relacional, que no es otra cosa que un mundo relacional en el que las relaciones sociales van más allá de lo humano para incorporarse al mundo socionatural y espiritual. Por ello, el ser no se define por su esencia en abstracto, sino por las relaciones prácticas que se manifiestan, por ende, tiene sentido hablar de inter-existencia. Para comprender que la vida es profunda y tiene interrelación, el antropólogo colombiano usa como ejemplo una flor: la flor inter-existe, para su existencia depende del agua, de la tierra, del ave, de la abeja, etc. Otro ejemplo que se podría proporcionar sería desde la biología: los ecosistemas inter-existen, las plantas necesitan de la luz solar, ellas proveen oxígeno a los animales y humanos, a su vez, se proporciona el dióxido de carbono necesario para las plantas, ellas también necesitan de agua y alimento igual que los animales; todo inter-existe. 
Para cerrar este apartado, se puede comprender no solo el giro ontológico en la antropología, sino que también se puede vislumbrar una nueva apuesta ontológica que es bastante pertinente, en cuanto que, si se quiere materializar la concepción de los pueblos indígenas zapatistas "un mundo donde quepan muchos mundos", resulta vital resignificar las teorías y prácticas que se realizan en nuestros mundos como comunidades y seres sociales que somos. Para ello, se deben decantar los enfoques investigativos y metodológicos con los que se piensa el mundo, para no continuar con lo que Orlando Fals Borda denominó el colonialismo intelectual, por consiguiente, para comprender que se está ante una diversidad de mundos, etnias, culturas, estructuras sociales $y$, a su vez, ante un multinaturalismo, es necesario un proceso comunicativo no dominador, que permita entender las necesidades vitales propias de un orden injusto y desigual, que aquejan de distintas formas a los pueblos.

\section{Activación política de la relacionalidad, hacia una ontología política}

Escobar (2012) manifiesta que el giro ontológico muestra los límites de la teoría social moderna, por ello, en el ámbito socionatural el giro da lugar a la activación política de la relacionalidad. Esto se debe a que los mundos relacionales conllevan una profunda relación con la lógica comunal de estar en y con los territorios, por ello cuando el territorio es vulnerado por dinámicas económicas y políticas, se está pasando por encima de la vida y la diversidad étnica, histórica y cultural, lo que trae como consecuencia la negación del buen vivir, como proyecto comunitario que busca una vida digna y que parte, sin duda alguna, del reconocimiento de la diversidad.

Así como se mencionó en el apartado anterior, el terreno político incluye a los nohumanos, lo que presupone a su vez comprender ontologías múltiples que parten desde las identidades territorializadas que se han apropiado de un espacio geográfico: territorialización. No obstante, se está ante un sistema-mundo y unas relaciones asimétricas globales, que han perjudicado también a las Américas, tal como pasa con la expansión de cultivo de palma de aceite para agrocombustibles en Colombia. De ahí que la ontología retome también las luchas políticas y sociales de las comunidades que han sido violentadas por la idea de "desarrollo" propia de la Modernidad. 


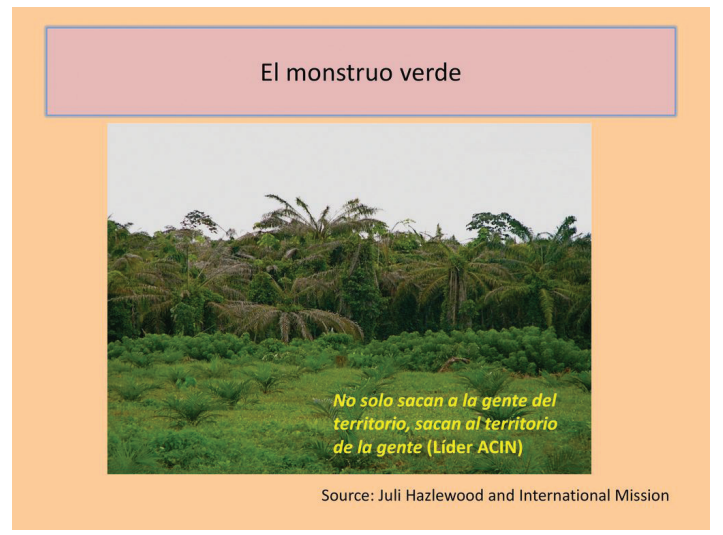

Figura 2. Desterritorialización desde la ontología de Arturo Escobar Fuente: Escobar (2015b).

La figura 2 ilustra que "la Modernidad como discurso y práctica no sería posible sin la colonialidad, y la colonialidad constituye una dimensión inescapable de discursos" (Maldonado Torres, 2007, p. 133). Esta afirmación conlleva dos análisis. El primero radica en aceptar la premisa de Aníbal Quijano (1998) y Nelson Maldonado Torres (2007), según la cual se debe pensar en la vigencia de la colonialidad del poder, del saber y del ser, en la medida en que ha acontecido la transición del colonialismo formal moderno a la colonialidad global. De cierta forma, esta última no es la clásica dominación desplegada por un poder económico militar sobre una nación específica, sino que se trata de una dominación que se expresa en las relaciones intersubjetivas (cultura, autoimagen de los pueblos, aspiración de los sujetos, proceso enseñanza-aprendizaje) y se articula al mercado mundial. Así pues, el discurso moderno sobre desarrollo, progreso y racionalidad está en disputa con la concepción de las comunidades que viven en los territorios, prueba de ello es la consulta popular en contra de la minería en ciertos territorios de Colombia.

El segundo análisis radica en la relación asimétrica de poder/ser, dominado/dominador, que conlleva prácticas que directamente agreden los pluriversos que se han construido con y en el territorio. La frase de la diapositiva de Escobar de una líder de la Asociación de los Cabildos Indígenas del Cauca es muy diciente: "sacan al territorio de la gente". Es decir, la visión moderna y occidental impide concebir el componente de la relacionalidad y la construcción de mundo, y comprender que cuando se desplaza a una comunidad de su territorio se niega el ser del ente que la comunidad es. 
Asimismo, Maldonado Torres acierta cuando manifiesta que "la colonialidad del ser aparece en proyectos históricos e ideas de civilización que incluyen, como parte intrínseca de estos, gestas coloniales de diversos tipos, inspiradas o legitimadas por la raza y el escepticismo misantrópico que la funda" (Maldonado Torres, 2007, p. 151). Cuando el autor menciona el escepticismo misantrópico hace referencia a una duda sobre lo obvio, con el propósito de poner en tela de juicio las alteridades para justificar su dominación, el ejemplo que proporciona Maldonado Torres (2007) es aquella discusión sobre si los indígenas tenían alma en la época de la invasión española a América, pues con esa pregunta se buscaba "comprobar" que no eran humanos y que era justa su empresa de dominación. De manera que el autor emplea este término para aquellas preguntas que expresan colonialidad en el subtexto.

La pregunta formulada por Maldonado Torres: “¿por qué piensas que tienes derechos?" (2007, p. 134), apoya una interpretación de la figura 3, ya que en esta imagen se evidencia cómo la palma desplazó a la comunidad de Tumaco y en medio de esta transformación quedó una de las casitas que estaban allí antes de la desterritorialización ocasionada por este cultivo. La pregunta que puede hacer la transnacional es: ¿por qué piensa la comunidad de Tumaco qué tiene derechos? Y, muy seguramente, como también lo comprende Escobar, plantear que hay un carácter relacional con el territorio, más allá de su función de sustento para la vida material, no es algo que los hombres, cuyas mentes ya han sido colonializadas por el mito de la Modernidad, puedan comprender.

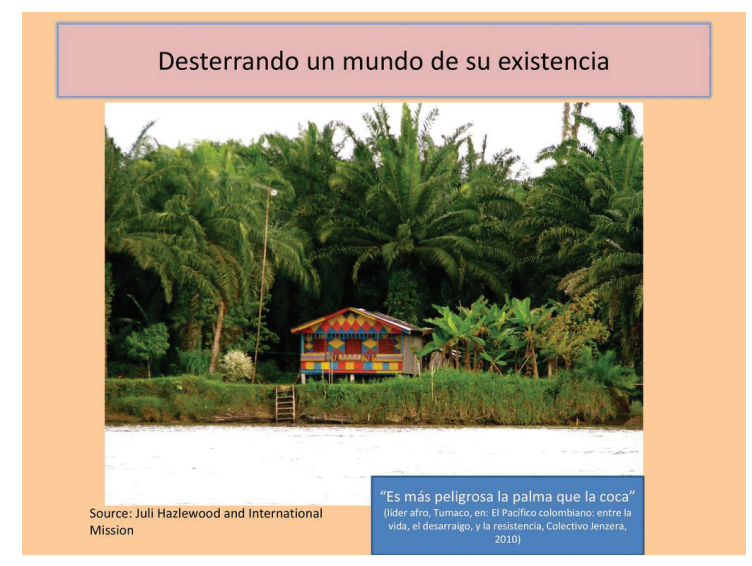

Figura 3. Colonización y luchas sociales en Arturo Escobar Fuente: Escobar (2015b). 
Siguiendo a Maldonado Torres, "el yo pienso, luego soy" de Descartes se presenta también bajo la dualidad "yo pienso otros no piensan", "yo soy, otros no son o están desprovistos de ser, por tanto, no deben existir o no son dispensables". Lo que trae como consecuencia que:

La expresión negativa y colonial de la conexión entre pensar y ser en la formulación cartesiana representa, quizás, el momento culminante en la transformación del escepticismo misantrópico en la certidumbre racional. [...] Descartes provee a la Modernidad los dualismos mente/cuerpo y mente/materia, que sirven de base para: 1) convertir la naturaleza y el cuerpo en objetos de conocimiento y de control; 2) concebir la búsqueda del conocimiento como una tarea ascética que busca distanciarse de lo subjetivo/corporal; 3) elevar el escepticismo misantrópico y las evidencias racistas, justificadas por cierto sentido común, al nivel de filosofía primera y de fundamento mismo de las ciencias. (Maldonado Torres, 2007, p. 145)

En este punto se vuelve al origen, ya que se retorna la mirada nuevamente a la Modernidad, a la ontología propuesta en ella que dio lugar a un dualismo que afirma la existencia de dos posibilidades de mundo, una que es y la otra (el pluriverso) que no es, he aquí las relaciones asimétricas del poder, denunciadas ya por la teoría decolonial y tenidas en cuenta por lo menos en la antropología:

Hay una relación asimétrica de poder entre la ontología cartesiana dominante de la Modernidad y las ontologías subalternizadas. Esa relación asimétrica es la colonialidad de la realidad - la reducción de una multiplicidad de mundos a una realidad hegemónica, la imposición de una realidad dominante sobre otras realidades, la negación de los mundos otros, en fin, un acto de imposición ontológica colonial-. (Burman, 2017, p. 165)

De ahí que las representaciones y la teoría sobre el modo de ser conlleven prácticas de colonización del ser, de las múltiples realidades. De manera que la respuesta de algunos pensadores como Escobar ha sido "mediante la introducción del concepto 'ontología política' y así contemplan las diferencias ontológicas sin perder de vista las luchas sociales y políticas, y las relaciones asimétricas globales del poder" (Burman, 2017, p. 161). Para establecer una práctica que tenga en cuenta que no todo funciona a partir del discurso moderno, que hay otras formas de ser y estar en el mundo, a su 
vez, existe un entretejido de mundos que conforman la realidad a nivel global, pero debido a la negación y desterritorialización de estos se hace necesaria una reivindicación por las luchas que libran las diferentes identidades en pro de su poder ser-estar.

Entonces, la concepción de Escobar consiste en apoyar todas aquellas luchas que resisten a ese proceso homogeneizador de Un Mundo, por ello se habla de luchas ontológicas que resulta vital apoyar si realmente se quiere tejer un pluriverso, "un mundo donde quepan muchos mundos". Como lo han venido planteando los zapatistas desde 1991 durante la Cuarta Declaración de la Selva de la Candona en el sureste mexicano, quienes han deseado que para todos sea todo, la voz de los que no tienen voz ha librado una lucha admirable por el reconocimiento. Tal vez si se deseara un ejemplo de "desobediencia ontológica", entendiendo por esta aquellos actos que desafían a la realidad impuesta y ejercen una proyección insurgente de otras realidades desde las prácticas cotidianas y rituales que pasan por la articulación de un proyecto político-ontológico (Burman, 2017), sería conveniente hablar también del Proceso de Comunidades Negras (PCN) con el que Escobar ha trabajado y al que ha dedicado largas horas de praxis:

Las comunidades negras hemos construido históricamente, durante 500 años, territorios ancestrales a partir de las luchas de nuestros ancestros por librarse de la esclavitud y manteniendo la memoria recreada por la gente negra traída del África. En estos territorios hemos recreado nuestras culturas, hemos resignificado nuestras creencias, hemos logrado la reproducción de nuestras vidas. La constitución de 1991 y la posterior expedición de la Ley 70 del 93 representaron un avance, aunque limitado, en nuestras aspiraciones por el reconocimiento de nuestra ancestralidad y nuestras raíces culturales étnicas. (PCN, 2012, citado en Escobar, 2015a, p. 94)

Las concepciones de mundo incluyen, sin duda alguna, visiones identitarias que son construidas culturalmente, por ello aquellas visiones que han sido fagocitadas desde una lógica occidental requieren reivindicar su historia, para desembocar no en un aislamiento, sino para reconocerse en la diversidad étnica y cultural que es la apuesta de una ontología política, en la que tendría que participar de alguna manera el Estado, que en teoría somos todos, aunque en la práctica no se evidencie. 
El trabajo de Escobar visibiliza, en gran parte, lo invisibilizado, puesto que la ontología política da cuenta de una lucha ontológica y epistémica al ser una reivindicación por otros mundos de y en la vida. Esta apuesta tiene dos ejes: uno teórico, en el que Escobar ha seguido a De Sousa Santos pues, así como él, admite que la comprensión del mundo es más amplia que la occidental, por consiguiente, los conocimientos de los movimientos sociales son esenciales para la comprensión del mundo y su posible transformación; el otro eje es práctico, ya que es el proceso con los pueblos y el territorio, tal como acontece con las comunidades afrodescendientes en el Pacífico. En palabras de Escobar:

La ontología política es entonces el análisis de mundos y de los procesos por medio de los cuales se constituyen como tales; esto aplica, obviamente, a la Modernidad misma. La ontología política resitúa al mundo moderno como un mundo entre muchos otros mundos. Esta es una tarea teórico política fundamental que se está abordando desde las academias críticas y desde ciertos movimientos sociales. [...] Haciendo eco a la sociología de las ausencias y las emergencias propuesta por Boaventura de Sousa Santos (2007), la ontología política busca visibilizar las múltiples formas de "mundificar" la vida, mientras que la práctica política ontológica contribuye a defender activamente estos mundos en sus propios términos. (Escobar, 2015a, p. 97)

De lo anterior se puede deducir una premisa simple: el campo político presupone una ontología, una visión de ser y estar en el mundo, como se ha venido desarrollando, no hay solo una forma de mundo, por tanto, si se está ante muchos mundos es imprescindible pensar en ampliar el horizonte de comprensión en pro de que las identidades y territorios de diferencia puedan salir de su estado de sumisión, propio de un mundo homogeneizante. Sin embargo, es necesario recalcar, una vez más, que se está ante una red asimétrica de poder, ser y saber, por ello las dinámicas político-económicas globales tales como el neoliberalismo, afectan de manera directa las ontologías relacionales y la respuesta no puede ser otra que la desobediencia ontológica y las luchas ontológico-epistémicas desde un plano político.

Así pues, las dinámicas globales han promovido el desarrollo, a través de discursos aún muy arraigados a la Modernidad. Para alcanzarlo se han utilizado las ideas de la Escuela de Chicago, cuyos pensadores le hicieron tanto daño a los menos favorecidos por el sistema económico y social, pues el neoliberalismo allí gestado, aplicado por 
primera vez en Chile durante la dictadura de Augusto Pinochet, le ha quitado poder al Estado y se ha valido de tácticas como la doctrina del shock, ideada por Friedman, que establece condiciones óptimas (desigualdad social) para impulsar el mercado. No obstante, lo que interesa en este artículo simplemente es referenciar que esta es una política agresiva que ha acentuado la colonialidad del poder $\mathrm{y}$, a su vez, del ser. Por ello no es extraño ver en la lucha por la defensa por el territorio en Colombia que las dinámicas de las multinacionales han llevado a la creación de enclaves económicos, como prueba de las relaciones asimétricas y coloniales en las que basan su actividad.

Para finalizar este apartado, vale la pena recalcar que la ontología política propuesta por Escobar es coherente con la definición que ha proporcionado sobre la relacionalidad, en cuanto que promueve el respeto por aquellas construcciones de mundo que nacen de la inter-existencia entre los seres que construyen y constituyen un territorio. Asimismo, como intelectual, Escobar lleva a cabo un acompañamiento en los territorios del Pacífico colombiano en la lucha por la defensa de la identidad y el territorio. De hecho, esta práctica establece un puente entre la ontología y la política. Sin embargo, tal como retoma la visión del PCN (2007), citada en Escobar (2015a):

Los territorios no son estáticos, como tampoco lo son los mundos, y nunca lo han sido. Al proponer que los territorios de las comunidades negras, constituyen una red compleja de relaciones en las cuales se desarrolla una propuesta político-organizativa que busca contribuir a la conservación de la vida, la consolidación de la democracia a partir del derecho a la diferencia, y la construcción alternativa de sociedad. (PCN, 2007, citado en Escobar, 2015a, p. 98)

En este orden de ideas, Silla y Renoldi (2016) manifiestan acertadamente que el giro ontológico es un intento por renovar la metafísica occidental y enlazarla con el pensamiento de los pueblos no-occidentales. Sin embargo, se equivocan al afirmar que este giro está poco preocupado por la filosofía política, ya que cuando se critica la crisis actual, el capitalismo y la Modernidad, ineludiblemente se está abarcando no solo un proyecto político, sino también una presuposición del ser y estar en un territorio específico. Escobar es una muestra de cómo lo político presupone una ontología, un fundamento sobre lo que está siendo en el mundo que a su vez inter-existe con otros. 


\section{Conclusiones}

Para concluir este texto, se puede inferir que el giro ontológico da lugar a varias ontologías que bajo la lógica de Occidente no tendrían sentido, pues como varios antropólogos han hecho evidente, es necesario ir más allá de las premisas dualistas que separan cuerpo/mente, individuo/otro y naturaleza/cultura. Por este motivo, una ontología radical de la diferencia parte necesariamente de rechazar la lógica cartesiana, pues todo lo que hace la cultura es una interpretación de lo natural, por ende, tiene sentido hablar de un multinaturalismo alrededor del que la cultura va a girar. Asimismo, es importante resaltar el trabajo de la teoría decolonial que no solo se separa de la visión eurocéntrica ontológica, sino que vuelve la mirada a la Modernidad, porque esta niega y asume la diferencia para homogeneizarla (fagocitarla) bajo procesos coloniales que se expresan en relaciones intersubjetivas y se articulan entre sí a través del mercado.

Ahora bien, sobre la propuesta ontológica de Escobar, resulta acertada su definición de que todos somos relacionalidad e inter-existencia, ya que posiblemente para llegar a la comprensión del ser habría que analizar el conjunto de relaciones que se dan en las comunidades, el ser está siendo en relación con el agua, los dioses, el mundo socio-natural, el otro... La comprensión relacional se puede expresar de muchas formas, puesto que no hay algo que esté separado, sino que todo está relacionado, cada parte que integra el todo que está siendo se enlaza a través de un vínculo con aquello que constituye y fundamenta su mundo. De manera que preexisten las relaciones que constituyen no solo al sujeto como ser comunitario, sino también al territorio. Dicho de otra manera, “no existe el 'individuo' sino personas en continua relación con todo el mundo humano y no-humano, y a lo largo de los tiempos. Lo humano y lo natural forman un mundo, con otras distinciones" (Escobar, 2012, p. 13).

Así pues, la ontología relacional presupone que cada visión de mundo tiene validez óntica y ontológica, ya que dimensiona que la totalidad de lo real está compuesta por una suma de elementos que no son míticos, metafóricos o simbólicos (todo lo anterior visto como algo despectivo), sino que presupone que hay otra forma de construir el mundo. Es en este punto donde la ontología vista desde la perspectiva filosófica resalta la propuesta de Escobar, en la medida en que se está reivindicando el nivel ontológico desde la comprensión existencial, pues esta implica que el ser se fundamente en un horizonte de cotidianidad. 
De manera que todo lo que está siendo se comprende desde un horizonte de sentido determinado por la cotidianidad, de ahí que el mundo sea una categoría que se enlaza con "lo que es ser" o "lo que está siendo". El mundo se integra al ser, porque es una totalidad de sentido cuyo fundamento parte del ser. La cultura se expresa en un conjunto de actos en la vida cotidiana y es en esa cotidianidad donde se manifiesta el ser como fundamento de esta.

Asimismo, es necesario mencionar que una de las categorías más valiosas de esta ontología relacional es pluriverso, ya que en ella se condensa el pensar el mundo y el universo compuesto por muchos mundos; tal como manifiesta Escobar (2015b), la comprensión de mundo es mucho más amplia de la que pudo pensar la Modernidad occidental. El reconocimiento de los conocimientos y el horizonte de comprensión vital existencial de las comunidades son necesarios para acabar con la homogeneización del ser y del saber.

Sumado a lo anterior, considero que el paso a seguir desde el horizonte teórico de Escobar es apalabrar su concepción del ser, ya que considero que es necesario para el antropólogo colombiano reevaluar la definición de Blaser (2008), citada por Escobar (2012), ya que, como bien lo identificaba Heidegger, "el ser no es algo así como un ente” (Heidegger, 2009, p. 25). El problema surge por el hecho de que para definir algo debemos recurrir a las categorías lógicas y estas no fueron elaboradas para hablar de algo que no sea ente. Asimismo, considero que para establecer un diálogo transdisciplinar sería muy enriquecedor brindar la definición de ser, para que la filosofía pueda aportar bases conceptuales y logre completar esta valiosa propuesta.

Por ejemplo, me atrevería a sugerir una comprensión también desde un enfoque transontológico (a partir del pensamiento de Dussel y Lévinas). Entiendo por esto una comprensión del ser no desde la totalidad en la que Occidente lo ha encapsulado, sino desde las relaciones prácticas que se develan desde el Otro, tal como lo manifestaba Lévinas, "abordar al ente a partir del ser, es, a la vez, dejarlo ser y comprenderlo" (Lévinas, 1977, p. 67). Lo que se propone en la ontología relacional va más allá de un horizonte ontológico tradicional y occidental, en cuanto que resulta en el otro, entendido como una comunidad cuyos vínculos se establecen desde su carácter de relacionalidad. 
De igual manera, Escobar tiene un punto de encuentro con Lévinas en la denuncia de la ontología, según la cual la única referencia al ser es fruto de una conciencia subjetiva cautiva de sí misma. Por ello no puede salir de sí para comprender al Otro o a los pluriversos, pues acierta Lévinas (1977) en decir que la razón soberana solo se conoce a sí misma y por esta razón da lugar a prácticas que sustentan afirmaciones como el desarrollo, un hecho en el que Escobar también ha reparado.

Asimismo, considero vital trabajar sobre las categorías ontológicas que proporcionarán el diálogo de mundos para su comprensión, puesto que creo que es relevante no caer en el relativismo de aceptar la multiplicidad de mundos, el pluriverso, pues mientras existan prácticas en la vida cotidiana que transgredan y vulneren aquellas ontologías que subyacen en los territorios y en las identidades que pueblan Latinoamérica, no da espera la creación de categorías que trabajen para crear diálogos, porque si bien es cierto que hay muchos mundos en un mundo, hay una visión de mundo homogeneizante que está imponiendo de diversas formas su lógica.

Por lo dicho anteriormente, no solo es necesario, tal como lo está haciendo valientemente Escobar, acompañar a las comunidades en su lucha ontológica política, sino que también es preciso un horizonte de compresión común que permita conversar sobre las herramientas que se necesitan para hacer posible y ampliar el buen vivir como proyecto indígena, afrodescendiente, campesino, de género y mestizo. Considero que la invitación de esta concepción de ontología radica en que la relacionalidad no debería particularizarse y atomizarse, sino que, por el contrario, debería buscar la manera de integrarse no para fagocitarse, sino para inter-existir con las visiones de otros mundos, finalmente, tenemos en común un mundo lleno de pluriversos.

\section{Referencias}

Aristóteles. (1990). Libro 7. En V. García Yebra (trad.), Metafísica (pp. 321-409). Madrid: Gredos.

Burman, A. (2017). La ontología política del vivir bien. En Ecología y reciprocidad: (con)vivir bien, desde contextos andinos (pp. 155-173). La Paz: Plural.

Dussel, E. (2016). Catorce tesis de ética. Madrid: Trotta.

Escobar, A. (2012). Cultura y diferencia: la ontología política del campo de cultura y desarrollo. Wale'keru, 2, 7-16. 
Escobar, A. (2015a). Territorios de diferencia: la ontología política de los "derechos al territorio". Desenvol. Meio Ambiente, 5(35), 89-100.

Escobar. A. (2015b). Arturo Escobar: tejiendo el pluriverso. [Archivo de video]. Recuperado de https://www.youtube.com/watch?v=p6KsJ-vDO7k\&t=1509s

Heidegger, M. (2009). Ser y tiempo. J. E. Rivera (trad.). Madrid: Trotta.

Lévinas, E. (1977). Totalidad e infinito. Ensayo sobre la exterioridad. Salamanca: Sígueme.

Maldonado Torres, N. (2007). Sobre la colonialidad del ser: contribuciones al desarrollo de un concepto. En El giro decolonial. Reflexiones para una diversidad epistémica más allá del capitalismo global (pp. 127-168). Bogotá: Siglo del Hombre.

Quijano, A. (1998). Estado-nación, ciudadanía y democracia: cuestiones abiertas. En H. González y H. Schmidt (eds.), Democracia para una nueva sociedad. Caracas: Nueva Sociedad.

Silla, R. y Renoldi, B. (2016). Ontologías: usos, alcances y limitaciones del concepto en antropología. Avá, 29, 7-25.

Tola, F. (2016). El “giro ontológico” y la relación naturaleza/cultura. Reflexiones desde el Gran Chaco. Apuntes de Investigación del CECYP, 27, 128-139. Recuperado de https://www.researchgate.net/publication/311982937_El_giro_ontologico_y_la_ relacion_naturalezacultura_Reflexiones_desde_el_Gran_Chaco 